Acta Poetica 28 (1-2)

PRIMAVERA-OTOÑO

2007

\title{
Huellas en el agua: las políticas de la memoria en Un cautivo enamorado de Jean Genet
}

\author{
Melina Balcázar Moreno
}

Frente a la gestión de las prácticas del duelo por el Estado — como los monumentos, las ceremonias de conmemoración que clausuran el acontecimiento y hacen olvidar a los muertos y su sufrimiento-, Jean Genet se rehúsa a elaborar el duelo y somete su escritura a un "deseo de memoria". ¿Cómo conservar las huellas del amigo muerto? ¿Cómo transformar su muerte en una afirmación de la vida que no implique una negación de la muerte? Ya que, para él, no basta con recordar a los muertos, con regresar al pasado mediante un acto de anamnesis continuo, casi obsesivo; si algo puede sobrevivir, no debe ser sino una imagen imperceptible, efímera, como "unas huellas en el agua". Esta lectura se interrogará así sobre el carácter paradójico de esta imagen en relación con la noción de acontecimiento.

Facing the gestion mourning practics for the State - as monuments and ceremonies of commemoration which adjourn the event and push to forget the dead and their sufferings-, Jean Genet refuses the elaboration of mourning and subjects his writing process to a "desire of memory". How to keep the traces of a dead friend? How to transform his dead into an affirmation of life that does not imply a denial of death? For Genet, it is not enough to remember the dead as a return to the past by means of an act of anamnesis almost obsessive. If there is something that could survive it could not be other than an ephemere imperceptible image, as "traces in the water". This form of reading questions the paradoxical character of this image in relation to the notion of event. 

Acta Poetica $28(1-2)$

PRIMAVERA-OTOÑO

2007

Melina Balcázar Moreno

Universidad de París VIII

Huellas en el agua:

las políticas de la memoria en

Un cautivo enamorado de Jean Genet

Es parte de la esencia de la imagen contener algo eterno. Esta eternidad se expresa mediante la firmeza y la estabilidad del trazo, pero puede también expresarse, de manera más sutil, gracias a una integración en la imagen misma de lo que es fluido y cambiante.

WALTER BENJAMIN

Habría que comenzar tal vez por la dedicatoria, esa escritura dirigida al amigo muerto. Desde sus primeros escritos, Jean Genet encuentra en la muerte del otro la única posibilidad de su escritura, su único punto de partida legítimo: "a Jean Decarnin" dedica Pompas fúnebres; "a un muerto joven", Los biombos. Pero ¿qué es lo que se produce cuando el otro muere? ¿Qué resulta de ello? ¿Qué es lo que resta? ¿Qué efecto? ¿Qué metamorfosis? Podría hablarse de una producción inaudita, de un acontecimiento paradójico: la producción de una 
desaparición. Por una parte, la desaparición del cuerpo, de su presencia empírica y, por otra, aquella de sí mismo, de un cierto sí mismo.

¿Cómo situarse entonces frente a esta desaparición? ¿Cómo hacer que este movimiento de escritura no se reduzca a una consolación? El problema que se plantea aquí consiste en saber de qué medios dispone la escritura para situarse frente a la muerte del otro, ${ }^{1}$ para encontrar una palabra que pueda seguir diciendo su amor, después de la pérdida. Así, Genet confronta en Un cautivo enamorado la dificultad que plantea hablar de los muertos, dirigirse a ellos:

Qu'on veuille bien comprendre que j'essaie de redire celui qui fut un homme de vingt-cinq ans, mort déjà depuis longtemps [...]. Chaque souvenir, moins qu'une goutte de parfum peutêtre, fait revivre l'instant défunt non selon sa fraîcheur vivante de cette époque, mais autrement, je veux dire revivant d'une autre vie. [...] Je ne ferai pas revivre Moubarak. [...] mais comment répondre à un mort autrement que par rhétorique ou silence $?^{2}$

Esta palabra que se debe a los muertos trabaja profundamente este "libro de recuerdos" y lo hace subvertir el objetivo inicial de los rituales de conmemoración, emprendidos por las fuerzas en el poder: producir una reconciliación política e histórica. Para él, la pérdida debe seguir siendo una pérdida y el silencio de los muertos debe ser conservado. Pero ¿cómo

\footnotetext{
${ }^{1}$ La escritura de Genet no surge únicamente como una reacción frente a la desaparición del amigo o del pueblo amigo, como en el caso de los palestinos, es también una forma de reaccionar ante otra modalidad de desaparición, aquella que se presenta en el espacio público: hay muertos que merecen ser llorados y otros a los que este derecho se les niega. Su escritura denuncia la prohibición de realizar el duelo públicamente y marca su posición estético-política frente a esta prohibición. Sobre este punto, el ensayo de Judith Butler, "Violence, Mourning, Politics" (Precarious Life. The Power of Mourning and Violence), ofrece una valiosa reflexión.

${ }^{2}$ Un cautivo enamorado, p. 405.
} 
puede la escritura responder a este imperativo si no es más que "una quijada de asno, más o menos vieja, oxidada, mal articulada"? ¿Cómo producir esta "bocanada de frescura [que] daría nuevamente una vida fugitiva al instante que pasó, pasó definitivamente" 3 en un medio que se revela insuficiente e imperfecto?

En agosto de 1983, Genet comienza, a petición de los palestinos, la redacción de Un cautivo enamorado:

Après les tueries de Sabra et Chatila en septembre 1982 certains Palestiniens me demandèrent d'écrire mes souvenirs. [...] lors de mon séjour à Vienne, je vis encore d'autres Palestiniens qui espéraient cette publication.

-Dis exactement ce que tu as vu, ce que tu as entendu. Essaye d'expliquer pourquoi tu es venu et si l'on veut accidentel. Tu es venu pour huit jours, pourquoi es-tu demeuré deux ans. ${ }^{4}$

Estas palabras enuncian lo que debería ser la tarea del escritor de acuerdo con cierta manera de entender el compromiso político: tendría que describir y contar exactamente, para dar testimonio y hacer justicia al movimiento palestino. Su deber no consistiría solamente en decir los hechos sino sobre todo en expresar su compromiso. Para apoyar esta causa, habría de explicar porqué se quedó durante dos años cuando en un inicio había emprendido un viaje de solamente algunos días. Sin embargo, si algún "compromiso" con esta causa acepta Genet, no sería el que se enuncia aquí; su tarea sería recibir en su escritura estas frases sin nombre, sin autor, sin pertenencia, que aparecen como un accidente de sintaxis ("et si l'on veut accidentel") y desestabilizan "su" gramática.

Para ser realmente fiel a este tiempo que pasó al lado de los palestinos, debe correr el riesgo de un desplazamiento o in-

\footnotetext{
${ }^{3}$ Idem.

${ }^{4}$ Ibid., pp. 330-331 (el énfasis es nuestro).
} 
cluso tal vez el de un perjurio: ante el acontecimiento histórico, Genet se concentra en lo más singular, y cuenta así, no los grandes hechos de esta lucha, sino aquellos acontecimientos que son los más frágiles, los más precarios y que poseen sin embargo una gran eficacia. Pero sin intentar probar nada, tomando al contrario solamente el tiempo de recobrar y de trabajar las huellas que han quedado en los cuerpos y en los lugares.

De esta manera, desplaza su testimonio del dominio de lo que puede ser probado al de lo que puede ser vivido e intenta restituir lo que experimentó durante su estancia en los campamentos palestinos:

Qu'un ancien combattant pour la millième fois me parle de la bataille de l'Argone, que Victor Hugo dans Quatre-Vingt-Trei$z e$ évoque les forêts bretonnes, m'agacera sans m'empêcher d'écrire encore et encore que les jours et les nuits passées sous les forêts d'Ajloun, de Salt à Irbid, aux bords du Jourdain, étaient une fête quand la définition de ce mot est celle-ci: le feu qui nous chauffe les joues d'être ensemble malgré les lois qui nous espèrent dans la déréliction [...]. L'exaltation dans la fête sera peut-être atteinte quand [...] le seul chant sera le bruit théâtral de la torsion de l'allumette noircie qui s'éteint. Cette dernière image fait songer que la fête se confond avec la veillée funèbre; en effet toute fête est simultanément jubilation et désespérance. ${ }^{5}$

En este pasaje se esboza otra figuración del acontecimiento, a partir de su temporalidad más profunda que es, como lo señala Georges Didi-Huberman, la temporalidad de lo que ha sido experimentado. ${ }^{6} \mathrm{Si}$ bien es cierto que es necesario producir una imagen a partir del pasado, ésta no debería de cir-

\footnotetext{
${ }^{5}$ Ibid., p. 494.

${ }^{6}$ Georges Didi-Huberman, Ouvrir les camps. Fermer les yeux, p. 26.
} 
cunscribirse al orden de lo verificable, no debería servir como prueba. Esta imagen del pasado haría coincidir durante un momento la fiesta y el velatorio. Para Genet, no basta con recordar a los muertos, con regresar al pasado mediante un acto de anamnesis continuo, casi obsesivo. ${ }^{7} \mathrm{Su}$ escritura busca encontrar el punto crítico ${ }^{8}$ que desajustaría el encadenamiento lógico y cronológico de la Historia o, más bien, de cierta idea de la Historia. Y ese punto crítico sería el instante, una vez salvado y disperso. ${ }^{9}$

Así, la escritura de Genet trabaja el instante, lo suspende y le da profundidad al hacerlo remontar a las percepciones originales que, sin embargo, no busca restituir sino más bien reencontrar su fuerza: ${ }^{10}$

Je fus agacé quand un jeune lionceau m'accueillit, presque solennellement $[\ldots]$ afin de me présenter le premier monument aux martyrs, dans le camp de Chatila [...] Mais tout mon séjour de plus d'un an et demi se fit pour ainsi dire porté sur une sorte de rayon, celui qui allait des yeux des deux feddayin, batteurs souriants de rythmes toujours nouveaux sur les cercueils. $^{11}$

\footnotetext{
${ }^{7}$ Aun cuando se sitúe dentro de la problemática de lo que actualmente se denomina el "deber de memoria", la escritura de Genet pone constantemente en cuestión esta obsesión conmemorativa que subyace en los actos de memoria promovidos por el Estado y por los medios de comunicación. En efecto, la memoria ha sido transformada en un asunto político que ha tomado la forma de un imperativo ético. La presente lectura intenta sin embargo distinguirse de esta toma de posición que domina hoy en día el espacio público. Ver sobre esta cuestión Enzo Traverso, Le passé, modes d'emploi.

${ }^{8}$ Walter Benjamin, Paris, capitale du XIX ${ }^{e}$ siècle. Livre des passages, pp. 479-480.

${ }^{9}$ Ver de Walter Benjamin, L'Origine du drame baroque allemand, p. 31.

${ }^{10} \mathrm{Y}$ es en este sentido como podría hablarse de una búsqueda estética no fenomenológica en el conjunto de la obra de Genet.

11 Un cautivo enamorado, pp. 348-349.
} 
A lo largo de Un cautivo enamorado se encuentra esta desconfianza con respecto a los monumentos dedicados ya sea a las víctimas o a los héroes de la revolución palestina. Esta crítica del monumento se dirige, por una parte, a su exaltación del heroísmo, que proviene de una estética del mártir relacionada con el nacionalismo y, por otra, a su sublimación e incluso embellecimiento del sufrimiento. En efecto, el monumento pone en marcha una retórica que fija la memoria y hace del dolor del otro "un pretexto para el poema", ${ }^{12}$ que neutralizaría el acto de memoria mediante una conmemoración, es decir, una reconciliación política y estética. Una política de la memoria que tome como fundamento el mármol corre el riesgo de anular el acontecimiento y de volver definitivo el sufrimiento de las víctimas del pasado, al exponer el cuerpo ofrecido en sacrificio y convertirlo en un paradigma del que habría que prolongar el ejemplo.

El rechazo de concebir el pasado como una unidad cerrada en sí misma abriría - y sobre este punto existiría más de un punto de coincidencia entre las escrituras de Genet y de Walter Benjamin - la única posibilidad revolucionaria. Si la revolución es aún posible, si puede acontecer en la poesía, sería justamente mediante esta apertura del pasado. En consecuencia, habría que hacer que el sufrimiento no sea definitivo, para lo cual la rememoración no sería suficiente. Habría entonces que trabajar de manera profunda el tiempo, a partir del equívoco y de la impureza del tiempo.

No obstante, parece querer decirnos Genet, no debería abandonarse la representación del cuerpo o la de sus marcas de sufrimiento a este tipo de dispositivo político. En su obra, lo esencial consiste en saber de qué manera la escritura podría conservar en la memoria los cuerpos desaparecidos, en su fragilidad, y las huellas que ha dejado su desaparición. Uno de

${ }^{12}$ Ibid., p. 421. 
los mayores intereses de su escritura residiría entonces en la deconstrucción del concepto de comunidad de mirada, en el que se basa el funcionamiento tanto de los medios de comunicación como de los rituales de conmemoración. ${ }^{13}$ Esta comunidad depende de una política que sobreexpone la muerte en el espacio público y que, según los términos de Ariella Azoulay, la "pone en el aparador". 14 A esta comunidad de mirada que intenta hacer aparecer la imagen perdida — para producir una reconciliación política y estética-, Genet opone una imagen en movimiento que pone de manifiesto esta desaparición:

Je laisse sur l'eau les traces déjà brouillées que les combattants veulent dans le marbre. Le livre que j'ai décidé d'écrire au milieu de 1983, qu'il pèse moins que la rougeur furtive du feddai se sauvant d'Ajloun. ${ }^{15}$

¿Qué política de la memoria suponen estas huellas en el agua? Estas huellas se arriesgan justamente a la conjunción paradójica de lo público y de la experiencia vivida, individual, frágil, volátil, efímera. La comunidad de mirada es desmontada mediante la tentativa de dar un lugar, en el espacio público, a un gesto de conmemoración íntimo, corporal, invisible. ${ }^{16} \mathrm{El}$ relato de la Historia (que corresponde al del monumento de

\footnotetext{
${ }^{13}$ Genet ha puesto en escena en repetidas ocasiones los mecanismos que sustentan esta comunidad en la mirada mediática. En la obra de teatro Elle, por ejemplo, asistimos a los bastidores de una sesión fotográfica de "su majestad el Papa". Una mirada nos es impuesta a través de la fotografía que intenta extender el poder de este notable personaje. Sin embargo, para el escritor, habría que dar a mirar esta imagen desde su soledad, desde su intimidad pues, a pesar de la fuerza que contienen en potencia, las imágenes son frágiles, así como el poder que busca afirmarse mediante ellas. El desplazamiento constante del dominio público al privado (y viceversa) le permite trabajar su mirada para poder leer de otra manera las imágenes y extraer de ellas su fuerza.

14 Ver Ariella Azoulay, Death's Showcase. The Power of Image in Contemporary Democracy.

${ }^{15}$ Un cautivo enamorado, pp. 447-448.

${ }^{16}$ Ariella Azoulay, op. cit., p. 6.
} 
mármol o de papel) es quebrantado por esta memoria que lleva la marca de lo equívoco de la experiencia vivida y del afecto. $\mathrm{Y}$ es precisamente el carácter singular y su transformación permanente lo que constituye su fuerza. ${ }^{17}$

Para que una palabra sobre el sufrimiento pueda considerarse como una palabra que actúa, como lo señala Luc Boltanski, debería intentar hacer que se aprehenda algo de esta precariedad del recuerdo - que es la fragilidad de la vida misma-, para oponerse a la violencia. ${ }^{18}$ La violencia de la que se trata aquí es la del espectáculo del cuerpo expuesto. Ya que el cuerpo no es solamente desgastado, desvastado por la miseria o la guerra, sino también por sus representaciones excesivas en el espacio público.

La relación de la escritura de Genet con la violencia es ciertamente muy compleja. En algunos de sus textos puede encontrarse una sobreexposición de la violencia (sexual) ejercida en el cuerpo, o bien, un elogio (fúnebre) de la pena capital. Y esta exposición del cuerpo que sufre se acompaña de la exhibición del cuerpo mismo del autor. No obstante, estas diferentes relaciones con la violencia — que se someten a una lógica del deseo- son debilitadas por su escritura al retraerse. En la obra de Genet, es particularmente interesante la articulación entre lo que podría llamarse una pulsión de exhibición - estrechamente ligada a los dispositivos del poder - y una crítica de esta misma sobreexposición que conduce al escritor a buscar otras estrategias de escritura. ${ }^{19}$

\footnotetext{
${ }^{17}$ Enzo Traverso, op. cit., p. 19.

${ }^{18}$ Luc Boltanski, La Souffrance à distance. Morale humanitaire, médias et politique.

${ }^{19}$ En una carta dirigida a Roger Blin, Genet escribe: "mis libros, así como mis obras, fueron escritos contra mí mismo. [...] Y si no lo consigo, sólo mediante mi texto, habría que ayudarme. Contra mí mismo, contra nosotros mismos, mientras que estas representaciones nos colocan de no sé que buen lado por el que la poesía no llega". Lettres à Roger Blin, Euvres complètes, t. IV, Paris, Gallimard, p. 259 (la traducción es nuestra). La exposición de sí mismo no se basa en un intento de
} 
Sin embargo, ¿es acaso posible recordar fuera del régimen de la mirada? ¿Es posible crear una comunidad conmemorativa sin este espacio público en el cual el horror (de la guerra, de la miseria) y el cuerpo que lleva las huellas de este horror aparezcan como espectáculo? ${ }^{20}$

Para responder al muerto, "de otra manera que mediante retórica o silencio", es necesario en efecto encontrar una imagen que diga la pérdida como pérdida sin borrar el dolor que causa: "Celui qui, vivant, sacrifie son unique vie devrait avoir droit à une sorte de pierre tombale de silence et d'absence à la fois le dissimulant en frappant d'irréalité quiconque prononce le nom ou évoque l'acte héroïque cause du mutisme définitif'. ${ }^{21}$

Un cautivo enamorado busca hacer del silencio una imagen que dure "el tiempo de un relámpago", 22 para retomar los términos empleados por Benjamin en sus tesis sobre la historia. La imagen no es una cuestión de perceptibilidad, es decir, una manera de dar presencia al pasado o de hacerlo aparecer. Se compone más bien de una configuración provisoria, equívoca y ambigua, de tiempos: ${ }^{23}$

Par [Abou Omar] je compris assez vite la vie très menue des Palestiniennes dans les camps. Composée des mêmes points de broderie des vieilles robes, la mémoire ancienne des Palestiniennes est un assemblage de mémoires minimales et momentanées mises à bout afin de savoir qu'il faut acheter du

\footnotetext{
autoafirmación, sino que es, por el contrario, una manera de minar el yo, de poner en cuestión la idea de un yo, de un nosotros soberano.

${ }^{20}$ Ariella Azoulay, op. cit., p. 78.

${ }^{21}$ Un cautivo enamorado, p. 406.

22 Walter Benjamin, "Sur le concept d'histoire".

23 A propósito de esta inversión de la noción de imagen, los escritos de Georges Didi-Huberman son fundamentales, en particular L'Image survivante. Histoire de l'art et temps des fantômes selon Aby Warburg (2002), así como la reflexión de Walter Benjamin, "Tesis de filosofía de la historia", La obra de arte en la época de su reproductibilidad técnica y El origen del drama barroco alemán.
} 
fil, coudre trois boutons, repriser un fond de culotte, retourner chez le marchand pour un peu de sel, et le temps qu'il faut pour tenir la bride dans l'épaisseur de l'oubli aux misères passées ou ajouter aux souvenirs indispensables, au sel, au fil, aux boutons, la mémoire des morts, des combattants, les œufs, le thé, quelle vie ininterrompue! ${ }^{24}$

¿De qué manera puede ser política una memoria? ¿Es posible darle una configuración que no forme parte de los diferentes usos políticos que se hacen de ella? ¿Puede hacerse un uso crítico de la memoria? Una memoria, entendida como "imagen del pasado", se vuelve crítica cuando se aprehende en el momento de peligro. Y el peligro que se vislumbra en este pasaje es el olvido, la caída del Antaño en el olvido. Pero la escritura de Genet da otra vida a esos "puntos de bordado de los viejos vestidos" al prolongar el trabajo de memoria de las mujeres palestinas para transformarlo en una "obra de vida". ${ }^{25}$

Otras políticas de la memoria se esbozan en la vida cotidiana de estas mujeres, en el punto crítico que hace encontrarse el Antaño (la memoria antigua del tejido) con el Ahora (las memorias mínimas y momentáneas). La memoria de los muertos se conserva así en este ensamblaje de tiempos, el de la tradición y el de lo vivido de todos los días.

Para oponerse a la violencia de la exhibición, parece entonces necesario renunciar al deseo de ver, de entrar en una economía de la vista que haga depender la memoria del espectáculo del cuerpo que lleva las huellas, las pruebas de lo experimentado. Pero este renunciamiento es al mismo tiempo una manera de renunciar a uno mismo, a un cierto uno mismo: "les Palestiniens sont certainement à l'origine d'un effondrement de mon vocabulaire". ${ }^{26}$ Un derrumbamiento que lo lleva

\footnotetext{
${ }^{24}$ Un cautivo enamorado, p. 312.

25 Jean Genet, Pompas fúnebres.

${ }^{26}$ Un cautivo enamorado, p. 367.
} 
a abandonar toda pretensión de mirar de manera autónoma, o incluso soberana, el movimiento palestino. ${ }^{27}$

¿Toda recuperación política de la escritura de Genet es verdaderamente imposible? ¿Su escritura lleva la marca de "una negatividad absoluta" 28 como ciertas lecturas insisten en afirmar actualmente? El lenguaje como lazo ¿ha sido sacrificado ${ }^{29}$ Una inmensa soledad separa, ciertamente, al escritor de sus lectores pero no es el resultado de ningún sacrificio. Otros lazos trabajan esta escritura, esta soledad, lazos que dan en la lengua misma un lugar al silencio de los muertos. Un deseo de memoria que la transforma profundamente.

"Mettre à l'abri toutes les images du langage et se servir d'elles, car elles sont dans le désert, où il faut aller les chercher." ¿Qué dice este desierto sin fin sino un llamado, casi una

\footnotetext{
${ }^{27}$ El ensayo de Edward W. Said, Orientalism, plantea los problemas a los que tiene que enfrentarse aquel que decide escribir sobre el Oriente, lo cual permite reconocer la importancia del proyecto emprendido por Genet: "[...] how to get hold of it, how to approach it, how not to be defeated or overwhelmed by its sublimity, its scope, its awful dimensions. Everyone who writes about the Orient must locate himself vis-à-vis the Orient; translated into his text, this location includes the kind of narrative voice he adopts, the type of structure he builds, the kind of images, themes, motifs that circulate in his text - all of which add up to deliberate ways of addressing the reader, containing the Orient, and finally, representing it or speaking in its behalf". La posición de Genet frente al "Oriente" busca separarse de este ejercicio de fuerza cultural que, según Said, ha caracterizado la relación entre Occidente y Oriente. Este derrumbamiento establecería otro nexo con la diferencia, un nexo que se situaría lejos de toda hostilidad.

${ }^{28}$ Cf. Éric Marty, Bref séjour à Jérusalem e Ivan Jablonka, Les Vérités inavouables de Jean Genet.

${ }^{29}$ Éric Marty, Bref séjour à Jérusalem, pp. 20-21. La obra de Genet va en contra de toda idea de pureza lingüística, política o ética que presupone la lectura de Marty. El escritor no introduce ninguna "corrupción al centro de todos los lazos simbólicos", como afirma Marty. Su escritura muestra por el contrario que la imposibilidad de hacer comunidad es constitutiva de lo político y en consecuencia del lenguaje mismo. Esta crítica de lo político entendido como una exigencia de hacer comunidad desmonta los mecanismos de esa violencia que exige que el nexo sea conservado a toda costa. La violencia de lo político se pone así de manifiesto a lo largo de su obra. Esta crítica demuestra que ninguna "ley de hierro rige el mundo" (Marty), ya que todo poder es asediado por una diferencia irreductible que muestra la ilusión sobre la que se funda el Estado nación.
} 
exigencia, para perder su campo de visibilidad, sus puntos de referencia? Para Genet, escribir es ponerse al descubierto, "sin el resguardo de una tienda", para ir hacia esa palabra "herida por la realidad y que busca la realidad", 30 retomando las palabras de Paul Celan quien también intentó responder a este llamado. Sin embargo, esta frase, errante y solitaria, dice también la tarea del escritor: ir al desierto para responder a la precariedad misma de las imágenes.

En esta búsqueda de las imágenes del lenguaje, se encuentra tal vez otra relación con la violencia. ¿Cómo producir, en efecto, el máximo de emoción a partir del mínimo de violencia? ${ }^{31}$ Pues sólo la emoción transmite y salva lo vivido. ${ }^{32} \mathrm{Ge}-$ net dibuja en la arena de ese desierto las líneas de lo que podría llamarse un "lirismo seco", 33 una emoción seca de la que extrae una imagen desértica que hace legible la pérdida y la desaparición del otro:

J'ai fait ce que j'ai pu pour comprendre à quel point cette révolution ressemblait peu aux autres et d'une certaine façon je l'ai compris, mais ce qu'il m'en reste sera cette petite maison d'Irbid où une nuit je dormis, et quatorze ans durant lesquels je tentai de savoir si cette nuit avait eu lieu. Cette dernière page de mon livre est transparente. ${ }^{34}$

\footnotetext{
${ }^{30}$ Paul Celan, "Discurso con motivo de la concesión del premio de literatura de la ciudad libre hanseática de Bremen”, p. 498.

31 Sobre este punto ver Véronique Fabbri, "Danse contemporaine et disparition", L'époque de la disparition. Politique et esthétique.

${ }^{32} \mathrm{Cf}$. "L'émotion très particulière que j'ai à tout hasard nommée poétique laissait en mon âme une espèce de sillage d'inquiétude qui allait s'atténuant. [...] Je demeurai attentif à saisir ces instants qui, errants, me paraissaient à la recherche, comme l'est d'un corps une âme en peine, d'une conscience qui les enregistre et les éprouve. L'ayant trouvée ils cessent: le poète épuise le monde". Journal du voleur, p. 181.

${ }^{33}$ Samuel Fuller, citado por Georges Didi-Huberman, Ouvrir les camps. Fermer les yeux, p. 44.

${ }^{34}$ Un cautivo enamorado, p. 504.
} 
Un cautivo enamorado, texto-cristal, denso y luminoso, se hace enigma en su transparencia. Y estas huellas en el agua son la imagen del pasado que Jean Genet nos entrega como una promesa. Lo que queda entonces es el testimonio de su amor, el silencio que se hizo posible por el espacio en blanco, un silencio que "no es un silencio, ninguna palabra ha enmudecido, ninguna frase, es simplemente una pausa, un blanco, un vacío". ${ }^{35}$ Le corresponde al escritor producir este intervalo, conservar esta línea blanca por la que el acontecimiento de escritura podría ocurrir. Este acontecimiento es la firma anónima del otro que trabaja en lo más profundo el texto. La tarea del escritor consistiría en velar porque este lugar sea conservado.

\section{BIBLIOGRAFÍA}

Azoulay, Ariella, Death's Showcase. The Power of Image in Contemporary Democracy, trad. Ruvik Danieli, Cambridge, Massachusetts, The Mit Press, 2001.

Benjamin, Walter, "Peintures chinoises à la Bibliothèque nationale", Ecrits français, Paris, Gallimard, 1991, pp. 259-262 (Bibliothèque des idées).

— "L'œuvre d'art à l'époque de sa reproductibilité technique", $C E u$ vres, t. III, trad. Maurice de Gandillac revisada por Pierre Rusch, Paris, Gallimard, 2000, pp. 269-316 (Folio Essais, 374).

- "Sur le concept d'histoire", CEuvres, t. III, trad. Maurice de Gandillac revisada por Pierre Rusch, Paris, Gallimard, 2000, pp. 427-443 (Folio Essais, 371).

Boltanski, Luc, La Souffrance à distance. Morale humanitaire, médias et politique, Paris, Métailié, 1993 (Leçons de choses).

Brossat, Alain y Jean-Louis Déotte (dir.), L'époque de la disparition. Politique et esthétique, Paris, L'Harmattan, 2000 (Esthétiques).

${ }^{35}$ Paul Celan, Diálogo en la montaña, Obras completas, p. 484. 
ButLer, Judith, Vie précaire. Les pouvoirs du deuil et de la violence après le 11 septembre 2001, trad. Jérôme Rosanvallon y Jérôme Vidal, Paris, Amsterdam, 2005.

Celan, Paul, Entretien dans la montagne, trad. André du Bouchet, Paris, Fata Morgana, 1996.

- "Allocution prononcée lors de la réception du prix de littérature de la Ville libre hanséatique de Brême", Le Méridien \& autres proses, trad. Jean Launay, Paris, Seuil, 2002, pp. 55-58 (La librairie du $\mathrm{XX}^{\mathrm{e}}$ siècle).

Didi-Huberman, Georges, L'Image survivante. Histoire de l'art et temps des fantômes selon Aby Warburg, Paris, Minuit, 2002.

- Gestes d'air et de pierre, Paris, Minuit, 2005.

- Ouvrir les camps, fermer les yeux, cycle de conférences, Mexico, enero de 2007.

GENET, Jean, Pompes funèbres, Paris, Gallimard, 1953 (L'Imaginaire).

- Lettres à Roger Blin, Euvres complètes, t. IV, Paris, Gallimard, 1979.

- Un Captif amoureux, Paris, Gallimard, 1986.

SAID, Edward, Orientalism, New York, Vintage, 1979.

Traverso, Enzo, Le Passé, modes d'emploi. Histoire, mémoire, politique, Paris, La Fabrique, 2005. 